\title{
Measuring Technical Efficiency of Faith Based Hospitals in Tanzania: An application of Data Envelopment Analysis (DEA)
}

\author{
Kembo M. Bwana ${ }^{1,2, *}$ \\ ${ }^{1}$ Accounting School, Dongbei University of Finance and Economics, No. 217, Jianshang \\ Street, Dalian, China \\ ${ }^{2}$ Department of Accounting, College of Business Education, Tanzania \\ *Correspondence: Tel: 86-131-2410-7402. E-mail: Kembo211@gmail.com \\ Received: November 10, 2014 Accepted: December 17, 2014 Published: February 9, 2015 \\ doi:10.5296/rae.v7i1.6597 URL: http://dx.doi.org/10.5296/rae.v7i1.6597
}

\begin{abstract}
By employing data envelopment analysis (DEA), this study examines efficiency of faith-based (private not for profit-PNFP) hospitals in Tanzania. Using data from 15 hospitals, particularly Volunteering Agency Hospitals (VAHs), our study period covered the year 20092012. The objective of this study is to determine technical efficiency of Volunteering Agency Hospitals (VAHs) as well as scale efficiency and hence establish how the inefficiency in these hospitals (VAHs) can be reduced in Tanzania. Significance of this Study premises on equipping the hospitals administrators, governing boards, owners as well as healthcare policy makers with relevant information on how to improve hospitals efficiency. Additionally, through deliberating on the generalization of efficiency of the faith-based hospitals the study will add to the existing literatures on the efficiency of religious hospitals particularly in Tanzania.
\end{abstract}

Based on measures of technical efficiency the average efficiency index (for all hospitals) was $0.769(76.9 \%)$ and total number of technically efficient was 4 (26.6\%) hospitals. The result shows that, average annual technical efficiency for the VAHs was $59.79 \%$ in the year 2009, $60.01 \%$ in the year 2010, 57.49\% in the year 2011 and $55.08 \%$ in the year 2012, which implies that there was no improvement in the technical efficiency. However, most of the hospitals (73.33\%) have increasing returns to scale (IRS) which means therefore that, if more resources will be equally allocated to these hospitals (with IRS) there will be proportionate increase in production of health services hence catching up the production frontier.

Keywords: Technical efficiency, Faith-based hospitals, Tanzania, Data Envelopment Analysis. 


\section{Introduction}

Efficiency is defined as the Pareto optimal allocation of resources (Aday et al., 1998). Pareto efficiency implies that the production system cannot increase unit of production without decreasing production of the other unit. Debru (1951) first measure the efficiency whereas Farrell (1957) revealed the simple measure of efficiency that could accommodate multiple inputs and outputs within the context of technical, allocative and productive efficiency. He suggested that, efficiency of any firm should consist of the two components; technical and allocative efficiency combining the two efficiency measures gives the measure of productive efficiency.

A firm is technically efficient when it produces the maximum outputs from a given amount of inputs or, produces a given output with minimum inputs quantities (Hollingsworth, 2008). The firm is locative efficient, when the inputs mix minimizes cost, given the price of inputs, or when the outputs mix maximizes revenue, given outputs prices. When the two taken together, technical and allocative efficiency comprise overall efficiency; when the firm is overall efficient, it operates on its cost or revenue frontier (Hollingsworth, 2008). Measuring the hospital efficiency plays an important and significant role in the evaluation of the health policy initiatives and comparatives analysis of health systems (Biorn et al., 2003; Gerdtharn et al., 1999). Studies conducted by Hollingsworth et al., (1999; 2003) on the systematic review of the studies on hospital efficiency and productivity has given a clear picture of general view of literatures on hospitals efficiency and productivity. Literatures record that most of the studies incorporated in the systematic review were from the developed countries. For example in the systematic review by Hollingsworth (2003) out of 188 studies/papers reviewed most of them are from developed. However, in recent years there have been a few studies on hospitals efficiency and productivity from developing countries such as Osei et al., (2005) Technical efficiency on Ghana's hospitals; Pilyavisky and Staat (2008) efficiency and productivity change on Ukraine's hospitals. Other studies include, Yawe (2010) Technical efficiency on the Uganda's district hospitals; Peckan(2011) Technical efficiency and profitability of hospitals associated with Government in Turkey; Kirigian et al., (2002) Technical efficiency of public hospitals in Kenya.

The Ministry of Health and Social Welfare (MoHSW) is responsible for policy, governance financing and quality assurance while the Prime Minister's Office Regional Administration and Local Government is the Implementer.

The rest of this paper is organized as follows; Section Two gives brief explanation of the objective and significance (motivation) of the study. Section three presents the methodology employed in this study, that is describing the selected variables, data set and the estimation techniques. Findings and analysis of the hospitals efficiency results, as well as discussion on findings, are presented in Section four. Conclusion and recommendation regarding the result of this study are shown in Section Five.

\section{Research Objectives and Significance of the Study}

\subsection{Research objectives}

General purpose of this study is to examine the efficiency of the faith-based hospitals in 
Tanzania. Specifically the assessment includes:

i. To compute and then evaluate technical efficiency of Volunteering Agency Hospitals in Tanzania

ii. To determine the scale efficiency and establish how inefficiency can be reduced in the Volunteering Agency Hospitals (VAHs).

\subsection{Significance of the study}

In healthcare systems, the assessment of efficiency is the important step in evaluating individual performance of production units such as hospital. It involves the rational frameworks for the distribution of resources between and within the health care facilities (Kontodimopolous et al., 2006; Moshiri et al., 2011). This study therefore, will provide valuable information (based on the efficiency assessment) to the necessary stakeholders who are very concern with reviewing, managing and auditing the performance of the faith-based hospitals in Tanzania. Managers and hospitals administrators can then decide on actions that have to be taken on inefficient hospitals (operating below the efficient frontier) to reach the efficient frontier, attains the efficiency score of one. Sexton and Harrison (2006) investigated the improvement of efficiency of the faith-based hospitals in USA. Therefore, inspired from a few empirical literatures on the efficiency of the faith-based hospitals it is important to examine the efficiency of the faith-based hospitals in Tanzania.

\section{Methodology}

The study is a descriptive analytic study, and the following faith-based hospitals were under scrutiny: Mbozi Mission Hospital, Lutembo Hospital, Nkinga Hospital, Mkula Hospital, Mbesa Mission, ST.Benedicts Hospital, Igongwe Hospital, Lugalawa Hospital, Uhai Baptist Hospital, Ilembula Hospital, Bukumbi Hospital, Iambi Lutheran Hospital, Nkoaranga Hospital, Marangu Hospital and Ndolage Hospital.

\subsection{Estimation techniques}

Data Envelopment Analysis (DEA) is the optimization based technique, that constructs an efficiency frontier by maximizing the weighted outputs/inputs ratio of each Decision Making Unit (DMU), given the constraint that the ratio can be equal but never exceed one (Chirikos and Sear, 2000; Ozcan, 2008). DEA was introduced into the literature by Charnes, Cooper and Rhodes (1978). Based on linear programming (LP). DEA as a Non-Parametric programming techniques it envelopes an efficiency frontier by optimizing weighted outputs -input ratio of each provider/firm (Decision-Making Units-DMUs) subject to the data set. In health care the first application of DEA dates on 1983 in the work of Nun maker and Lewin (1983) who measured the nursing services efficiency. Since then, DEA has been widely used in measuring the hospitals technical efficiency in the USA, as well as other part of the world at different levels of business and public sector operation.

DMUs in the context of this study are faith-based hospitals under the study (Volunteering 
Agency Hospitals-VAHs). Hospitals whose efficiency score is equal to one are said to be 'optimally efficient' when compared with other hospitals in the same sample. Such hospitals lie on the efficiency frontier. On the other hand hospitals whose efficiency scores are less than one are said to be 'operating inefficiently' and the lower the efficiency scores the more inefficiently the hospital is operating. DEA is designed to measure the relative efficiency in situations where, there are multiple inputs and outputs and there is no obvious objective way of aggregating either inputs or outputs into a meaningful index of productive efficiency (Ozcan, 2008). DEA technique determines the 'best practice' frontier that is built empirically from the observed inputs and outputs and then each decision-making units is compared with its peers. According to Coelli et al.,(1998) DEA is the preferred method of efficiency analysis in the non-profit sector where:

i. Random noise is less of a problem;

ii. Multiple outputs production is relevant;

iii. Price data is difficult to find; and

iv. Setting behavioral assumptions such as profit (cost) maximization (minimization) is difficult.

\subsection{Model selection and measurement of variables}

There are several types of DEA models, based on the assumption made about the management process. The model will be input or output-oriented (Cooper, Seiford and Tone, 2007). Input oriented model focus on the extent to which the firm can minimizes inputs without changing output quantity, while output models focus on how the firm can maximize the output without altering the input quantities. The other model is non-oriented which assumes that managers have control over both inputs and outputs rather than giving primacy to either (Ozcan, 2008).choice of the model depend on the objectives in questions. However, inputs oriented Data Envelopment Analysis (DEA) model is most useful for efficiency measurement in hospitals, because hospitals have more control on inputs rather than outputs (Pekcan et al, 2011)- for that case this study adopts the inputs oriented model to measure the hospitals' technical efficiency. Furthermore, DEA model also involve the assumption of Constant Return to Scale (CRS) and Variable Returns to Scale (VRS). The Constant Return to Scale (CRS) assumes that there is linear, proportional change in outputs for changes in inputs while Variable Return to Scale (VRS) assumes that returns are dependent upon change in volumes. In additional the VRS model is considered as the suitable in measuring hospital efficiency (Ozcan, 1992) - since units (hospitals) in the study vary by the size (number of beds etc). Therefore, in this study we adopt the Variable Return to Scale (VRS) model with assumption that these faith based hospitals in Tanzania vary by size.

Technical efficiency (TE), given the assumption underlying our study; input-oriented measured and variable return to scale (VRS); can be calculated by solving the following DEA LP problems. 


\section{Macrothink}

$\operatorname{Min} \lambda_{j}$, such that:

$$
\begin{aligned}
& \sum_{j=1}^{n} \lambda j Y r j \geq Y r o,(\mathrm{r}=1 \ldots \ldots \ldots \mathrm{n}) \\
& \sum_{j=1}^{n} \lambda i X i j \leq \theta X i o,(\mathrm{i}=1,2) \\
& \sum_{j=1}^{n} \lambda j=1, \quad \lambda \mathrm{j} \quad \geq 0 \quad(\mathrm{j}=1 \ldots \ldots \mathrm{n})
\end{aligned}
$$

The objective of the LP problem in (1) is to find the min that particularly reduces inputs vector to Xio, while guaranteeing at least the output level of Yro. The optimal solution to the LP problem is $\mathbf{T E}=\mathbf{0} \leq \mathbf{1}$ where $\mathbf{T E}=\mathbf{1}$ indicates a point on the efficient frontier and hence the technically efficient hospitals $\mathrm{TE}<1$, meaning that it is possible to produce the observed level of outputs using less than all inputs. Since the study aims at measuring efficiency, variables to be included in this study are categorized into inputs and outputs. Inputs variables are those that define resources used to produce outputs. Generally, DEA inputs in healthcare studies consist of variables representing labor, capital assets and/ or other operating expenses (Ozcan, 1992). This study follows Granneman et al., (1986) that the inpatients days factor is more medically homogeneous unit than the inpatient factor, therefore the use of inpatient days can provide more favorable hospitals efficiency. Finally, the use of surgical operation output is used because it requires different combination of inputs (such as specialized equipments and personnel) compared to other medical care. Building on the Pharm (2010) all outputs employed in this study are aggregate, and measuring hospitals outputs by such aggregate variables does not capture the case mix variation and quality of services provided. The absence of data in developing countries makes applicability of Diagnostic Related Group

\begin{tabular}{|c|c|}
\hline Outputs & Output operational definitions \\
\hline Total inpatients days & $\begin{array}{l}\text { Total number of days that the inpatients stayed in the hospital } \\
\text { and received inpatients services within the year 2009-2012. }\end{array}$ \\
\hline Total outpatients visits & $\begin{array}{l}\text { Total number of outpatients visited the departments during } \\
2009-2012\end{array}$ \\
\hline Surgical operation & $\begin{array}{l}\text { Total number of inpatients and ambulatory surgeries services } \\
\text { from theater during } 2009-2012\end{array}$ \\
\hline Inputs & Inputs operational definitions \\
\hline Licensed hospitals beds & Total Number of actually used Hospital beds during 2009-2012 \\
\hline $\begin{array}{l}\text { Full-time equivalent } \\
\text { employees } \\
\text { employees/staff }\end{array}$ & $\begin{array}{l}\text { Total number of full-time employees (both medical and } \\
\text { non-medical) during 2009-2012 }\end{array}$ \\
\hline
\end{tabular}
(DRG) limited (Zere et al, 2006; Pilyavisky and Staat, 2008) - Tanzania being one of the case.

Table 1. Inputs and Outputs Variables for DEA

Regarding the outputs variables, our study follows the study on the hospitals efficiency by $\mathrm{Hu}$ 
and Huang (2004), Chang et al.., (2004). Hospitals outputs in this study are proxied by outpatient visits, inpatient days and surgical operation performed. On the other hand, the inputs variables employed in the assessment of the hospitals efficiency are Full-time employees and hospitals' beds. The two inputs are considered to be proxies for the recurrent and capital resources spend in the running of hospitals. For this reason, summary of inputs and outputs employed in this study include (Table 1 above).

\subsection{Data collection and data set}

Data for this study were obtained partly from the library of the Christian Social Services Commission (CSSC) headquarter in Dar es Salaam, and some of the data have been achieved from the annual reports of the respective hospitals under the study. The data set covers period of 4 years from 2009 - 2012. The sample size used in this study was 15 volunteering Agency hospitals (VAHs) operating as Private not for Profit (PNFP) hospitals in Tanzania. These hospitals were chosen because they fulfill the requirements of the demand of this study since they are purely independent from the government control and operated by the faith-based organizations. Other faith-based hospitals which are Council Designated Hospitals (CDHs) were not included in the sample since the Government has influence over their operation and largely finance their operations. Choice of the study period was due to flexibility and the completeness of the data required; this was because during the period of 2009-2012 most of the hospitals annual reports contained the complete report. Kerr et al., (1999) argued that in assessing the hospitals' efficiency using DEA, it is advised to have a relatively short period of time when unmeasured dimensions of outputs can be expected to vary little.

\section{Results and Discussion}

Descriptive statistics for the inputs and outputs measures for the VAHs are given in table 2 . Total number of observations were 60 implying (4 years for 15 hospitals) since this is the panel data study.

Table 2. Summary Statistics of Hospitals' Variables (inputs and outputs)

\begin{tabular}{llllll}
\hline Variable & obs & Mean & Std. Dev & Min & Max \\
\hline totalinpat $\sim \mathrm{s}$ & 60 & 35168.29 & 25286.82 & 1494 & 115362 \\
totaloutpa $\sim \mathrm{t}$ & 60 & 19808.57 & 16400.46 & 3672 & 63806 \\
totalsurgi $\sim \mathrm{n}$ & 60 & 1833.583 & 1233.148 & 289 & 6732 \\
numberofbeds & 60 & 193.1167 & 80.0428 & 80 & 320 \\
fulltimest $\sim \mathrm{f}$ & 60 & 1363.917 & 1036.405 & 26 & 2329 \\
\hline
\end{tabular}

The summary of results of the hospitals efficiency is indicated in Table 3; analysis and discussion are presented in this part of the paper. 
Table 3. Efficiency Summary

\begin{tabular}{|c|c|c|c|c|}
\hline Hospital & CRSTE & VRSTE & Scale Eff & RTS \\
\hline 1 & 0.937 & 1.000 & 0.937 & decreasing \\
\hline 2 & 0.856 & 1.000 & 0.856 & decreasing \\
\hline 3 & 1.00 & 1.00 & 1.000 & - \\
\hline 4 & 0.643 & 0.926 & 0.694 & decreasing \\
\hline 5 & 1.00 & 1.00 & 1.00 & - \\
\hline 6 & 1.00 & 1.00 & 1.00 & - \\
\hline 7 & 0.933 & 1.000 & 0.933 & increasing \\
\hline 8 & 0.953 & 0.993 & 0.960 & increasing \\
\hline 9 & 1.00 & 1.00 & 1.00 & - \\
\hline 10 & 0.590 & 0.605 & 0.974 & decreasing \\
\hline 11 & 0.344 & 0.633 & 0.543 & increasing \\
\hline 12 & 0.406 & 0.573 & 0.709 & increasing \\
\hline 13 & 0.379 & 0.707 & 0.536 & increasing \\
\hline 14 & 1.00 & 1.00 & 1.00 & - \\
\hline 15 & 0.489 & 0.495 & 0.9880 & increasing \\
\hline Mean & 0.769 & 0.862 & 0.875 & \\
\hline \multicolumn{2}{|c|}{ Note: CRSTE } & \multicolumn{2}{|c|}{$=$ technical efficiency from CRS DEA } & \\
\hline \multicolumn{2}{|c|}{ VRSTE } & \multicolumn{2}{|c|}{$=$ technical efficiency from VRS DEA } & \\
\hline \multicolumn{2}{|c|}{ Scale Eff } & \multicolumn{2}{|c|}{$=$ scale efficiency $=$ CRSTE $/$ VRSTE } & \\
\hline \multicolumn{2}{|c|}{ RTS } & Scale & & \\
\hline
\end{tabular}

Based on the hospital's efficiency summary, result shows that only 5 hospitals $(33.33 \%)$ were technically efficient based on the CRSTE, meanwhile the $66.66 \%$ were observed to be inefficient. During the four years of the study difference/variation among hospitals was not so big for the first 9 hospitals as far as technical efficiency is concerned, as most of hospitals had efficiency scores ranging between 1 and 0.643 . However, there were considerable variations for the last six hospitals (Ref: Table 3 and Fig 1). During the study period the maximum technical efficiency score was 1 while the lowest was $0.316,0.288,0.234$ and 0.243 in the year 2009, 2010, 2011 and 2012 respectively.

However, the result of scale efficiency shows that only $5(33.33 \%)$ hospital were technically efficient while all other remaining hospitals portrayed scale inefficiency during the period under the study. The trend of scale efficiency tends to follow the patterns of technical efficiency. Figure 1 shows the trend/variations of CRSTE, VRSTE and Scale Efficiency in the hospitals during the study period. Generally, in view of the totality of our results VAHs portrayed the regressing trend with regards to technical efficiency and scale efficiency since only 6.66 per cent of all hospitals were efficient in each case and the variation in each follow the same direction. It is obvious that the number of hospitals lacking efficiency improvement was not decreasing during the study period and this is not a good indication as far as hospitals (VAHs) performance is concerned.

Measuring the return to scale involved the question of whether there will be an increase in 
production in case all resources are equally increased. In this aspect there are two elements: Constant Return to Scale (CRS), and Variable Returns to Scale (VRS). The Constant Return to Scale (CRS) assumes that there is linear, proportional change in outputs for changes in inputs while Variable Return to Scale (VRS) assumes that returns are dependent upon change in volumes (Ozcan, 1992). Meanwhile, VRS can either lead to Increase in return to scale (IRS) where equal increase in all factors of production lead to more production, or Decrease return to scale (DRS) where equal increase in all factors of production lead to less production or Constant Returns to Scale (CRS) where equal increase in all factors of production lead to the same amount of production. As far as the technical efficiency is concerned in the year 2009 three $(20 \%)$ hospitals had inputs with DRS, in the following year 2010 the hospitals with DRS increased to 4 (26.6\%). In the year 2011 the number of hospitals with DRS inputs decreased to 3 hospitals $(20 \%)$ while in the year 2012 it increased to $4(26.6 \%)$ hospitals. In totality during the year 2009, 2010, 2011 and 2012 eleven (73.3\%) hospitals had IRS, only two hospitals had CRS.

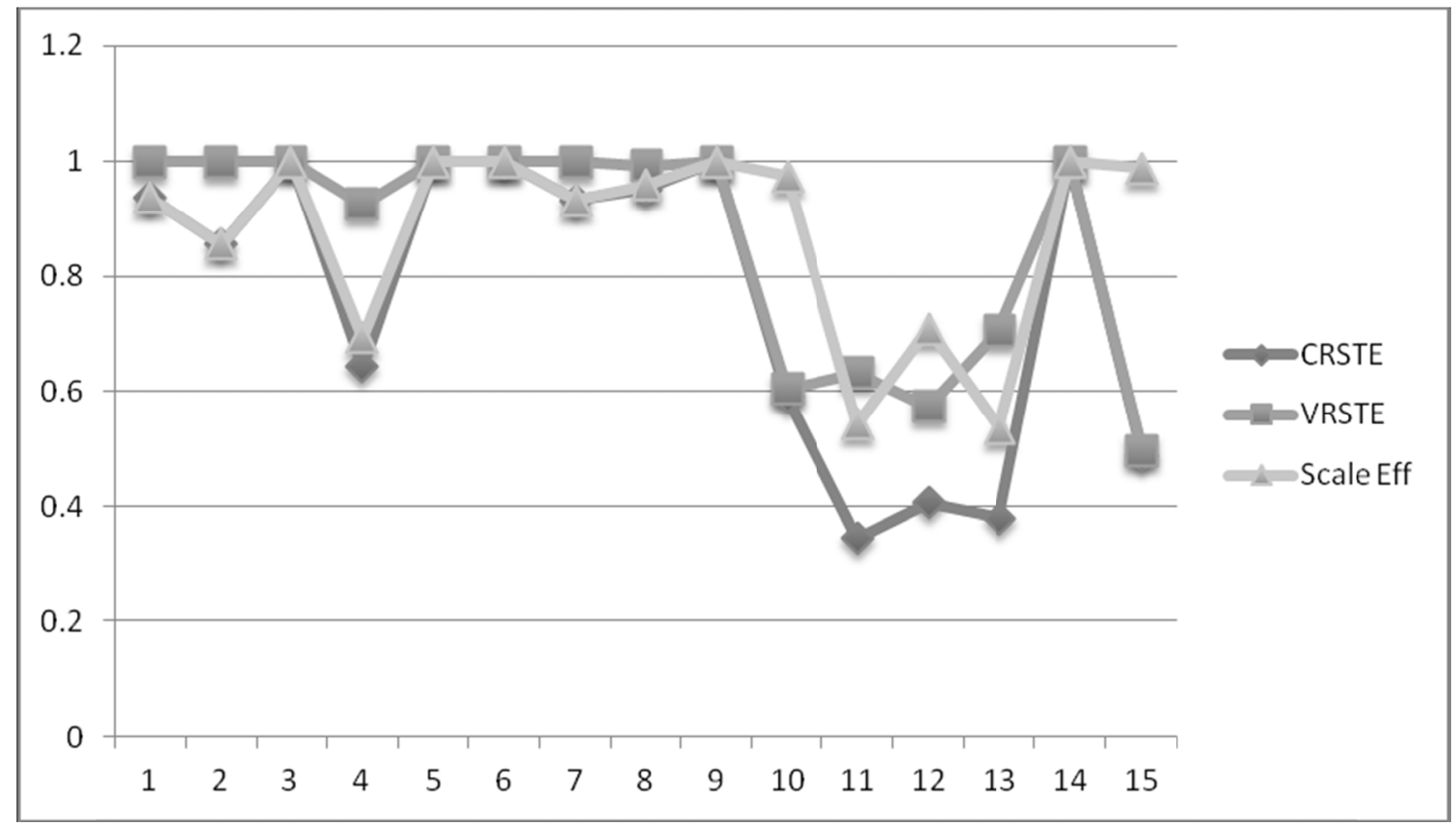

Figure 1. Hospitals' Technical and Scale Efficiency, 2009- 2012

Besides the fact that most of the hospitals were operating inefficiently, most of the hospitals (11 out 15$)(73.33 \%)$ have increasing returns to scale (IRS) which means therefore that, if more resources would have been added to these hospitals (with IRS) there could be an increase in production of health services hence catching up the production frontier (improving their efficiency).

Generally, based on measures of technical efficiency the overall average of the efficiency index (for all hospitals) was $0.769(76.9 \%)$ and total number of technically efficient was 5 $(33.33 \%)$ hospitals. The results show that average for the annual technical efficiency for the VAHs was $59.79 \%$ in the year 2009, 60.01\% in the year $2010,57.49 \%$ in the year 2011 and $55.08 \%$ in the year 2012 which implies that there were no improvement in the technical 
efficiency. When compared to the study conducted in US by Harrison and Sexton (2006) where there was improvement of religious hospitals from $72 \%$ in the year 1998 to $74 \%$ in 2001, the efficiency of (religious hospitals )VAHs in Tanzania has deteriorated during the study period. Furthermore, the number of hospitals operating on the production frontier has proved to be lacking improvement.

\section{Conclusion and Policy Implications}

This study is an attempt to present different dimensions of efficiency and the extent to which the efficiency can be improved. Our findings records that there were no improvement in the efficiency of VAHs in Tanzania, since in 2009 the technical efficiency scores was $59.79 \%$ and in 2012 it was $55.08 \%$. This indicates that VAHs are becoming inefficient in managing their resources. However, with regards to improvement of efficiency/reducing inefficiency there is a promising sign of IRS, convincing the Government and owners of these VAHs to inject more resources. This implies that 73.33 percent of these hospitals could have attained more production if more resources would have been equally increased.

The study possesses the policy implication on the resources allocation to VAHs in Tanzania. Since the Government has the role as the care taker for the health of its citizens, and it has been supporting the VAHs in terms of resources, both Government and owners of these VAHs are obliged to work together to improve the efficiency of these VAHs through resources provision. However, resources should be increased to the hospitals with IRS as the strategy to increase the number of efficient hospitals. As our study revealed $73.33 \%$ of VAHs hospitals had IRS. Conclusively, Hospitals administrators and managers should also adopt strategies that enhance combination of inputs that will improve efficiency (as well as minimizes the loss). The study suggests that future research should increase the sample size as well as study period and focus specifically on the root causes of the inefficiency in these VAHs in Tanzania.

\section{Acknowledgement}

I am grateful for the guidance and invaluable comments provided by Professor. Fang Hongxin (my supervisor). The paper has also gained constructing comments from anonymous reviewers.

\section{References}

Aday, LA., Begley, CF., Lairson, DR., \& Siater, CH (1998). Evaluating the health care system: effectiveness, efficiency and equity ( ${ }^{\text {nd }}$ Ed.). Chicago, Health Administration Press.

Biorn, E., Hagen, TP., Lversen, T., \& Magnussen, J. (2003). the effect of Activities based financing of hospital efficiency: A Panel Data analysis of DEA efficiency scores 
1999-2000. Health management science, 6, 271-83.

Chang, H., Chang,W., Das, S., \& Li, S. (2004). Healthcare regulation and operating efficiency of hospitals: Evidence from Taiwan. Journal of accounting and public policy, 23(6), 484-510. http://dx.doi.org/10.1016/j.jaccpubpol.2004.10.004

Charnes, A, Cooper, W., \& Rhodes E. (1978). Measuring the Efficiency of Decision Making Units. European Journal of Operation Research, 2(6), 429-444. http://dx.doi.org/10.1016/0377-2217(78)90138-8

Chirikos T., \& Sear S. (2000). Measuring Hospital Efficiency. A Comparison of Two Approaches. Health services research, 34(6), 1389-1408.

Coelli, T.J., Rao, SP., \& Battesse. (1998). An introduction to Efficiency and Productivity Analysis. Boston Kluwer Academic Publishers.

Cooper, WW. Seiford, L., \& Tone, K. (2007). Data Environment Analysis. A Comprehensive Text with Models, Application, references and DEA- Solver software. (2nd ed.). Springer, New York 2007

Farrell, MJ. (1957). The measure of productive efficiency. Journal of the royal statistical society series - General, 120(3), 253-290. http://dx.doi.org/10.2307/2343100

Gerdtham,U.G., Rehberg, C., \& Tambour, M. (1999). The impact of internal market on health care efficiency. Evidence from the healthcare reforms in Sweden. Applied Economics, 31, 935-45. http://dx.doi.org/10.1080/000368499323652

Grannemann, TW., Brown, RS., \& Puly, MV. (1986). Estimating the hospital costs: A multiple outputs analysis. Journal of Health Economics, 5(2), 107-27. http://dx.doi.org/10.1016/0167-6296(86)90001-9

Harrison, JP., \& sexton C. (2006). The Improving Efficiency Frontier of Religious Not for Profit Hospitals. Heldref Publication, 84(1), 2-10.

Hollingsworth, B. (2003). Non parametric and parametric applications measuring efficiency in healthcare. Healthcare management Science, 6(4), 203-18. http://dx.doi.org/10.1023/A:1026255523228

Hollingsworth, B. (2008). The Measurement of Efficiency and Productivity of Health Care Delivery. Health economics, 17(10), 1107-1128. http://dx.doi.org/10.1002/hec.1391

Hollingsworth, B., Dawson, PJ., \& Maniadakis, N. (1999). Efficiency measurement of healthcare: A review of non parametric methods and applications. Healthcare management Science, 2(3), 161-72. http://dx.doi.org/10.1023/A:1019087828488

Kerr, CA., Glass, CJ., Mc Callion, G., \& McKillop, G. (1999). Best Practice Measure of Resources Utilization for Hospitals': A useful complement in the performance assessment. Journal of Public Administration, 77(3), 639-650. http://dx.doi.org/10.1111/1467-9299.00172 
Kirigia, JM., Emrouznejad, A., \& Sambo, LG. (2002). Measurement of technical efficiency of public hospitals in Kenya. Using DEA. Journal of Medical Health System, 26, 39-45. http://dx.doi.org/10.1023/A:1013090804067

Kontodimopontos, N., Nanos, P., \& Niakas, D. (2006). Balancing efficiency of health services and equity of Access in remote areas in Greece. Health policy, 76, 49-57. http://dx.doi.org/10.1016/j.healthpol.2005.04.006

Moshiri, H., Aljunid, S., Amin, RM., Dahlui, M., \& Ibrahim WN. (2011). Measruing Efficiency Of Teaching Hospitals In Malaysia. International Journal of Business Management, 6(4), 207-213. http://dx.doi.org/10.5539/ijbm.v6n4p207

Nunamaker, T. R. (1983). Measuring routine nursing service efficiency: a comparison of cost per patient day and data envelopment analysis models. Health Services Research, $18(2$ Pt 1), 183.

Osei, D., d'Almaida, S., George, O., Kingia, M.J., Mensah, AO., \& Kainyu, LH. (2005). Technical Efficiency of Public District Hospitals and Health Centers in Ghana: A Pilot Study. Cost Effectiveness and Resources Allocation, 3(9). http://dx.doi.org/10.1186/1478-7547-3-9

Ozcan YA. (1992). Sensitivity analysis of hospitals efficiency under alternative outputs/inputs and peer Groups: a reviewer, knowledge and politics, 5, 1-29.

Ozcan YA. (2008). Healthcare Benchmarking and Performance Evaluation: An Assessment of DEA. Springer, Norwell, MA. http://dx.doi.org/10.1007/978-0-387-75448-2

Peckan, YA., Atan, M., \& Beylik, U. (2011). Evaluation And Analysis On Profitability-Efficiency In Hospital Affiliated With Ministry Of Health. Scientific Research and Essay, 6(28), 5837-5845.

Pham, TL. (2010). Efficiency and productivity of hospitals in Vietnam. Journal of Health Organization and Management, 25(2), 195-213. http://dx.doi.org/10.1108/14777261111134428

Pilyasvky, AI., \& Staat, M. (2008). Efficiency and productivity change in Ukrainian Healthcare. Journal of Productivity analysis, 29, 143-54. http://dx.doi.org/10.1007/s11123-007-0070-6

Yawe, B (2010). Hospital Performance Evaluation in Uganda. A Super efficiency Data Envelopment Analysis. Zambia Social Science Journal, 1(1), 79-105.

Zere, E., Mbeeli, T., Shangula, K., Mandlhate, C., Muterua, K., Tjivambi, B., \& Kapenambili W. (2006). Technical efficiency of district hospitals: Evidence from Namibia Using Data Envelopement Analysis. Journal of cost effectiveness and resources allocation, 4(5). http://dx.doi.org/10.1186/1478-7547-4-5 


\section{Copyright Disclaimer}

2015, Vol. 7, No. 1

Copyright for this article is retained by the author(s), with first publication rights granted to the journal.

This is an open-access article distributed under the terms and conditions of the Creative Commons Attribution license (http://creativecommons.org/licenses/by/3.0/). 